Jpn. J. Med. Sci. Biol., 51, Suppl. 1, S108-S114, 1998

\title{
Virulence of Shiga Toxin-Producing Escherichia coli (STEC) in Orally-Infected Mice Correlates with the Type of Toxin Produced by the Infecting Strain
}

\author{
Angela R. Melton-Celsa, James E. Rogers, Clare K. Schmitt, \\ Stephen C. Darnell and Alison D. O'Brien \\ Department of Microbiology and Immunology Uniformed \\ Services University of the Health Sciences, 4301 Jones Bridge Road, \\ Bethesda, MD, U.S.A.
}

\section{OVERVIEW}

In this chapter, we will provide a brief review of the attributes of the Shiga toxin (Stx) family with emphasis on the importance of these toxins in the pathogenesis of disease caused by $E$. coli $\mathrm{O} 157: \mathrm{H} 7$ and other Shiga toxin-producing $E$. coli (STEC). We will also describe a modification of our streptomycin (str)-treated, orally-infected mouse model $(23,24)$ that permits the assessment of the relative virulence of various $E$. coli $\mathrm{O} 157: \mathrm{H} 7$ strains. In addition, we will illustrate how the type(s) of Stx produced by an $E$. coli strain is linked to virulence of that isolate when fed to str-treated mice. Lastly, we will underscore the role that activation of Stx $2 \mathrm{~d}$ by intestinal mucus plays in enhancing the pathogenicity of an infecting STEC strain that produces Stx2d.

\section{Characteristics of Stxs}

\section{BACKGROUND}

Shiga toxin produced by Shigella dysenteriae type 1, which is considered the prototype for the Stx family, was first described in 1903 by Conradi (2) and, independently, by Neisser and Shiga (14). Over the ensuing 95 years, Shiga toxin has been purified to homogeneity, characterized biologically and biochemically, and the genes encoding the toxin cloned and sequenced [reviewed in (17)]. In aggregate, these studies taken with $\mathrm{X}$-ray crystallographic analysis (3) have culminated in a picture of Shiga toxin as a bi-partite molecule that is comprised of a single A polypeptide 
of $\sim 32 \mathrm{kDa}$ and a pentamer of B polypeptides of $\sim 7.7 \mathrm{kDa}$ each. The A polypeptide can be nicked and reduced into an enzymatically active $\mathrm{A}_{1}$ fragment and an $\mathbf{A}_{2}$ fragment. The $\mathbf{A}_{2}$ peptide functions to non-covalently link the $A_{1}$ polypeptide to the pentamer of $B$ or receptor-binding polypeptides. The enzymatic activity of this potent cytotoxin for Vero and $\mathrm{HeLa}$ cells is that of an $\mathrm{N}$-glycosidase that selectively removes a purine residue from 28S rRNA which, in turn, shuts down protein synthesis in the eucaryotic target cell (17). The receptor for Shiga toxin is globotriaosylceramide $\left[\left(\mathrm{Gb}_{3}\right)(17)\right]$.

Shiga toxin of $S$. dysenteriae type 1 (Stx) is the same toxin as Stx1 produced by many $E$. coli O157:H7 strains and related STEC (17). Most strains of $E$. coli O157:H7 also make Stx2. Stx1 and Stx2 share about $56 \%$ deduced amino acid sequence homology, but polyclonal antiserum to Stx2 does not cross neutralize Stx1 or vice versa (17). Stx/Stx1, Stx2, and Stx2-related toxins have the same general structure and mode of action. However, Stx/Stx1 expression is repressed by high concentrations of iron, whereas Stx 2 production is not iron-regulated. Some of the Stx family members also differ in specific toxic activity for tissue culture cells or for mice injected either intraperitoneally or intravenously with purified toxin preparations. Additionally, the virulence of STEC strains in orally-infected mice depends largely on the type of Stx produced by the infecting strain (discussed below).

\section{Shiga toxin-producing Escherichia coli (STEC)}

That certain diarrheagenic $E$. coli strains make a toxin related to Shiga toxin was first described by our laboratory in an abstract in 1978 (18) and subsequently confirmed in a peer-reviewed publication in 1982 (15). On a parallel tract, Konowalchuk and colleagues reported in 1978 that some $E$. coli isolates make a toxin that kills Vero cells (8). We subsequently showed that these Vero cell toxins and the Shiga toxins of $E$. coli were different names for the same proteins (16). Indeed, production of Stxs was ultimately demonstrated to be a hallmark trait of enterohemorrhagic $E$. coli (EHEC) O157:H7, the most common infectious cause of bloody diarrhea in the United States and the most frequent preceding event for the development of the hemolytic uremic syndrome (HUS) [see ref. (4) for a comprehensive review of $E$. coli $0157: \mathrm{H} 7$ ]. EHEC [so named by Levine (9)] are a subset of STEC that in addition to maintenance of a large plasmid and synthesis of Stxs also express the adhesin intimin. Intimin is encoded in the locus of enterocyte effacement (LEE), a newly described pathogenicity island that is also found in enteropathogenic $E$. coli (12). The epidemiological link between Stx production by an E. coli 
isolate and the development of HUS after infection by that strain was established by Karmali and colleagues in their seminal papers $(6,7)$.

\section{RELATIONSHIP BETWEEN RELATIVE TOXICITIES OF DIFFERENT STXS FOR MICE AND VIRULENCE OF STEC IN A MOUSE ORAL INFECTION MODEL}

\section{Mouse model for 0157:H7 and non-0157 STEC}

We previously showed that streptomycin (str)-treated outbred CD-1 mice succumbed to infection when fed $10^{10}$ organisms of a mouse-passaged strain of E. coli $\mathrm{O} 157: \mathrm{H} 7$ strain 933cu (cu for cured of its large plasmid), even though neither the parent $933 \mathrm{cu}$ strain nor 933 was virulent at $10^{10}$ organisms (23). We later found that this mouse-virulent strain, designated 933cu-rev, had acquired the capacity to grow on the distal small bowel epithelium and in mouse small intestinal mucus (23). We speculated that these acquired traits permitted increased systemic toxin delivery from the intestine compared to the parent $933 \mathrm{cu}$ strain. We also discovered that death of the mice fed 933cu-rev was due to tubular necrosis mediated by Stx2, but not Stx1, produced by the strain (24). Subsequently, we tested a panel of Stx1- and/or Stx2-producing E. coli O157:H7 strains as well as non-O157 strains in the str-treated CD-1 mouse model. We now conclude that an STEC strain is likely to be pathogenic in this CD-1 model if it either: i.) grows in small-intestinal mucus, colonizes the large intestine of the mice, and makes Stx2 or Stx2c [high oral $50 \%$ lethal dose $\left(\mathrm{LD}_{50}\right)$ ] or Stx2d (low oral LD 50 , see below); or ii.) synthesizes very high levels of Stx2, Stx2c, or Stx2d (as expressed from a clone) and colonizes only the large bowel [see Table 1 as well as refs. $(10,24)$ for details on relative virulence of STEC strains for CD-1 mice]. More recently, we discovered that certain E. coli $0157: \mathrm{H} 7$ strains that make Stx1 and Stx2 or Stx2

Table 1. Correlation between toxicity of Stx type and virulence in mice

\begin{tabular}{ccccc}
\hline Toxin type & $\begin{array}{l}\text { LD } 50 \text { after intra- } \\
\text { peritoneal injection } \\
\text { of mice }\end{array}$ & \multicolumn{2}{l}{$\begin{array}{l}\text { Oral LD } \\
\text { indicated toxin in str-treated }\end{array}$} & $\begin{array}{c}\text { Activated by } \\
\text { intestinal mucus }\end{array}$ \\
\cline { 2 - 4 } & CD-1 mice & DBA/2J mice & \\
\hline Stx1 & $400 \mathrm{ng}$ & Not virulent & Not virulent & No \\
Stx2 & $0.5-2 \mathrm{ng}$ & $\sim 10^{10}$ & $<10^{2}$ & No \\
Stx2c & ND & $\sim 10^{10}$ & ND & No \\
Stx2d & $1-5 \mathrm{ng}$ & $<10$ & $<10$ & Yes \\
Stx2e & $200 \mathrm{ng}$ & Not virulent & ND & No \\
\hline
\end{tabular}

a) ND, not determined. 
Table 2. Virulence of $0157: \mathrm{H} 7$ strains in str-treated, orally-infected DBA/2J mice

\begin{tabular}{cc}
\hline $\begin{array}{c}\text { Toxin }(\mathbf{s}) \\
\text { produced }\end{array}$ & $\begin{array}{l}\text { No. virulent strains/ } \\
\text { no. of } \text { strains tested }\end{array}$ \\
\hline Stx 1 & $0 / 2$ \\
Stx2 & $3 / 3$ \\
Stx $1+2$ & $1 / 3$ \\
\hline
\end{tabular}

Table 3. Stx2-specific antibody protects $\mathrm{DBA} / 2 \mathrm{~J}$ mice from lethal infection with an O157:H7 strain that produces both Stx1 and Stx2

\begin{tabular}{lc}
\hline Treatment $^{a)}$ & No. survivors/no. infected \\
\hline PBS & $0 / 5$ \\
MAb 13C4 $(\alpha-\mathrm{Stx} 1)$ & $0 / 5$ \\
MAb 11E10 $(\alpha-\mathrm{Stx} 2)$ & $5 / 5$ \\
\hline a) Administered to DBA/2J mice intraperitoneally $(0.1 \mathrm{ml} l) 24$ hours before \\
and 24 hr after oral infection with 109 CFU of O157:H7 strain 2812 \\
(produces Stx1 and Stx2).
\end{tabular}

alone that are avirulent in str-treated CD-1 adult mice are pathogenic if fed to streptomycin-treated DBA/2J mice, Table 2. As with 933cu-rev in CD-1 mice, it is Stx2 that kills DBA/2J mice fed a virulent E. coli 0157 :H7 strain that produces both Stx1 and Stx2 (see Table 3). In fact, E. coli O157:H7 strains that make Stx1 only are avirulent in DBA/2J mice. That Stx2 is about 400-fold more toxic for mice when injected parenterally than is $\operatorname{Stx} 1[(21)$ and summarized in Table 1] probably explains the differences in virulence among these strains. Of note is the correlation between this observation that Stx2 and Stx2-related toxins contribute to virulence of STEC in a mouse model whereas Stx1 does not, and the finding that Stx2-producing $E$. coli $0157: \mathrm{H} 7$ more frequently cause HUS than those that make Stx1 only (19). The fact that certain O157:H7 strains that produce Stx2 or Stx2 and Stx1 are virulent in $\mathrm{DBA} / 2 \mathrm{~J}$ mice but not in CD-1 mice could be explained by differences in the size of the animals. Indeed, we speculate that virulence in this model is not only due to type of toxin but also level of toxin produced relative to body weight of the mouse. Four observations support various aspects of this hypothesis: i.) male DBA $/ 2 \mathrm{~J}$ mice weigh about $17 \mathrm{~g}$ while adult $\mathrm{CD}-1$ mice weigh about $24 \mathrm{~g}$; ii.) a str-resistant $E$. coli $\mathrm{K}-12$ strain transformed with a multicopy plasmid encoding Stx2 or Stx2d is sufficient to cause kidney damage and kill orally-infected adult CD-1 mice (11,24); iii.) EHEC 0157:H7 strain 86-24 (Stx2-producer) has a low $\mathrm{LD}_{50}$ in adult 
DBA/2J animals but a high $\mathrm{LD}_{50}$ in adult CD-1 mice (see Table 1); and, iv.) adult inbred mice of approximately the same size as DBA/2J mice ( $\mathrm{C} 57 \mathrm{BL} / 6 \mathrm{~J}, \mathrm{BALB} / \mathrm{cJ}$, and $\mathrm{C} 3 \mathrm{H} / \mathrm{HeJ}$ ) are also susceptible to lethal infection with strain 86-24 (unpublished observation). Whatever the actual basis of the sensitivity of adult DBA/2J mice to many Stx2- or Stx1- and Stx2-producing E. coli O157:H7 strains, we propose that this mouse model is appropriate for evaluating relative virulence of such isolates.

\section{Enhanced virulence of Stx2d-producing non-0157 strains in the CD-1 mouse model}

When we began to screen various strains of STEC for mouse virulence, we made the startling discovery that STEC O91:H21 strain B2F1 killed str-treated adult CD-1 mice when fed at doses as low as 10 organisms (10). We also identified another O91:H21 strain, designated H414-36/89 (10), that was similarly virulent for these large mice. We proposed that the extraordinary pathogenicity of these isolates might be due to the production Stx2d toxins [originally called Stx $2 \mathrm{vh}$, see ref. (10)] by these strains. In fact, we later showed that the toxicity of Stx2d can be increased (activated) by exposure to mouse or human colonic mucus and that this capacity for activation is unique to the Stx2d variant of Stx2 [see Table 1 and ref. (13)]. More recently, we identified other non-O157 STEC strains that are highly virulent for str-treated CD-1 mice [e.g. an $\mathrm{O} 104: \mathrm{H} 21$ isolate, 3024-94, that caused an outbreak of hemorrhagic colitis in the U.S. in $1994(1)]$ and found that they also make Stx2d (unpublished finding). To date Stx2d is the only Stx that we have identified which can be activated by intestinal mucus. The only amino acid differences that can account for the fact that Stx2d is activatable but not Stx2 or Stx2c (13) are two amino acids in the C-terminus of the $\mathrm{A}_{2}$ fragment of those toxins (13). We are in the process of identifying which of these amino acids are critical for activation and defining the biochemical basis for activation. We also intend to explore how activation actually translates into increased toxicity.

\section{CONCLUSION}

The type of Stx produced by an infecting STEC strain directly relates to its virulence in a str-treated orally infected mouse model: Stx/Stx1 is less toxic than Stx2 or Stx2c, and Stx2 and Stx2c are less toxic than Stx2d. Adult CD-1 mice are less sensitive than DBA/2J mice to these toxins as delivered following oral infection; hence, the DBA $/ 2 \mathrm{~J}$ model can be used to screen $\mathrm{Stx} 2{ }^{+}$O157:H7 strains for relative virulence. Finally, 
the low oral $\mathrm{LD}_{50}$ of non-O157 isolates that make Stx2d appears to be directly related to the fact that the toxicity of these proteins increases in the presence of intestinal mucus.

\section{REFERENCES}

1. Centers for Disease Control and Prevention. (1995): Outbreak of acute gastroenteritis attributable to Escherichia coli serotype O104:H21- Helena, Montana, 1994. MMWR 44 : 501-503.

2. Conradi, H. (1903): Ueber iösliche, durch aseptische Autolyse erhaltene Giftstoffe von Ruhr- und Typhusbazillen. Dtsch. Med. Wochenschr. 29:2628.

3. Fraser, M.E., M.M. Chernaia, Y.V. Kozlov, and M.N.G. James. (1994): Crystal structure of the holotoxin from Shigella dysenteriae at $2.5 \AA$ resolution. Structural Biology $1: 59-64$.

4. Griffin, P.M. (1995): Escherichia coli O157:H7 and other enterohemorrhagic Escherichia coli. p.739-761. In M.J. Blaser, P.D. Smith, J.I. Ravdin, H.B. Greenberg, and R.L. Guerrant. (ed.), Infections of the gastrointestinal tract. Raven Press, Ltd. New York.

5. Karch, H., J. Heesemann, R. Laufs, A.D. O’Brien, C.O. Tackett, and M.M. Levine. (1987): A plasmid of enterohemorrhagic Escherichia coli O157:H7 is required for expression of a new fimbrial antigen and for adhesion to epithelial cells. Infect. Immun. $55: 455-461$.

6. Karmali, M.A., M. Petric, C. Lim, P.C. Fleming, G.S. Arbus, and H. Lior. (1985): The association between idiopathic hemolytic uremic syndrome and infection by verotoxin-producing Escherichia coli. J. Infect. Dis. $151: 775-782$.

7. Karmali, M.A., B.T. Steele, M. Petric, and C. Lim. (1983): Sporadic cases of haemolytic-uraemic syndrome associated with faecal cytotoxin and cytotoxinproducing Escherichia coli in stools. Lancet i : 619-620.

8. Konowalchuk, J., J.I. Speir, and S. Stavric. (1977): Vero response to a cytotoxin of Escherichia coli. Infect. Immun. 18 : 775-779.

9. Levine, M.M. (1987): Escherichia coli that cause diarrhea: enterotoxigenic, enteropathogenic, enteroinvasive, enterohemorrhagic, and enteroadherent. J. Infect. Dis. $155: 377-389$.

10. Lindgren, S.W., A.R. Melton, and A.D. O'Brien. (1993): Virulence of enterohemorrhagic Escherichia coli $\mathrm{O} 91: \mathrm{H} 21$ clinical isolates in an orally infected mouse model. Infect. Immun. $61: 3832-3842$.

11. Lindgren, S.W., J.E. Samuel, C.K. Schmitt, and A.D. O'Brien. (1994): The specific activities of Shiga-like toxin type II (SLT-II) and SLT-II-related toxins of enterohemorrhagic Escherichia coli differ when measured by Vero cell cytotoxicity but not by mouse lethality. Infect. Immun. 62:623-631.

12. McDaniel, T.K., K.G. Jarvis, M.S. Donnenberg, and J.B. Kaper. (1995): A genetic locus of enterocyte effacement conserved among diverse enterobacterial pathogens. Proc. Natl. Acad. Sci. USA $92: 1664-1668$.

13. Melton-Celsa, A.R., S.C. Darnell, and A.D. O'Brien. (1996): Activation of Shiga-like toxins by mouse and human intestinal mucus correlates with 
virulence of enterohemorrhagic Escherichia coli $\mathrm{O} 91: \mathrm{H} 21$ isolates in orally infected, streptomycin-treated mice. Infect. Immun. $64: 1569-1576$.

14. Neisser, M. and K. Shiga. (1903): Ueber freie Receptoren von Typhus- und Dysenteriebazillen und über das Dysenterietoxin. Dtsch. Med. Wochenschr. 29 : 61-62.

15. O'Brien, A.D. and G.D. LaVeck. (1982): Immunochemical and cytotoxic activities of Shigella dysenteriae 1 (Shiga) and Shiga-like toxins. Infect. Immun. 35 : 1151-1154.

16. O'Brien, A.D., T.A. Lively, M. Chen, S.W. Rothman, and S.B. Formal. (1983): Escherichia coli O157:H7 strains associated with haemorrhagic colitis in the United States produce a Shigella dysenteriae 1 (Shiga) like cytotoxin. Lancet i : 702.

17. O'Brien, A.D., V.L. Tesh, A. Donohue-Rolfe, M.P. Jackson, S. Olsnes, K. Sandvig, A.A. Lindberg and G.T. Keusch. (1992): Shiga toxin: biochemistry, genetics, mode of action, and role in pathogenesis. p.66-94. In P.J. Sansonetti. (ed.), Pathogenesis of Shigellosis. Berlin-Heidelberg, Springer-Verlag.

18. O'Brien, A.D., M.R. Thompson, J.R. Cantey, and S.B. Formal. (1977): Production of a Shigella dysenteriae-like toxin by pathogenic Escherichia coli. abstr. B-103. 77th Annu. Meet. Am. Soc. Microbiol. (Abstract)

19. Ostroff, S.M., P.I. Tarr, M.A. Neill, J.H. Lewis, N. Hargrett-Bean, and J.M. Kobajashi. (1989): Toxin genotypes and plasmid profiles as determinants of systemic sequelae in Escherichia coli O157:H7 infections. J. Infect. Dis. 160 : 994-998.

20. Renwick, S.A., J.B. Wilson, R.C. Clarke, H. Lior, A.A. Borczyk, J. Spika, K. Rahn, K. McFadden, A. Brouwer, A. Copps, N.G. Anderson, D. Alves, and M.A. Karmali. (1993): Evidence of direct transmission of Escherichia coli O157:H7 infection between calves and a human. J. Infect. Dis. 168 : 792-793.

21. Tesh, V.L., J.A. Burris, J.W. Owens, V.M. Gordon, E.A. Wadolkowski, A.D. O'Brien, and J.E. Samuel. (1993): Comparison of the relative toxicities of Shiga-like toxins type I and type II for mice. Infect. Immun. $61: 3392-3402$.

22. Waddell, T., S. Head, M. Petric, A. Cohen, and C. Lingwood. (1988): Globotriaosyl ceramide is specifically recognized by the Escherichia coli Verocytotoxin 2. Biochem. Biophys. Res. Commun. 152 : 674-679.

23. Wadolkowski, E.A., J.A. Burris, and A.D. O'Brien. (1990): Mouse model for colonization and disease caused by enterohemorrhagic Escherichia coli O157: H7. Infect. Immun. $58: 2438-2445$.

24. Wadolkowski, E.A., L.M. Sung, J.A. Burris, J.E. Samuel, and A.D. O'Brien. (1990): Acute renal tubular necrosis and death of mice orally infected with Escherichia coli strains that produce Shiga-like toxin type II. Infect. Immun. 58 : 3959-3965. 